\title{
Prevalence of diabetes in the Southern region of Mexico
}

\section{Brief summary}

The aim of this mini review is to show the prevalence of diabetes in the Southern region of Mexico so as to highlight the importance of developing diabetes observational and prospective studies in this region of the country.

\section{Mini review}

The worldwide prevalence of diabetes has increased from $4.7 \%$ to $8.5 \%$ in the adulthood population (1980-2019) (www.who.int/). According to the International Diabetes Federation in 2017, there were 451 million people (aged 18 to 99 years old) who suffered from diabetes worldwide and it is expected to have increased significantly to 693 million by $2045 .{ }^{1}$ Diabetes is a chronic metabolic disease of variable etiology and with social, behavioral, environmental and genetic risk factors, which make the disease study more complex. The most common form of diabetes is type 2 diabetes (T2D) and it is presented in $90-95 \%$ of all adult patients with diabetes ${ }^{2}$. That phenomenon occurs because obesity has been getting more and more common among youngster populations worldwide. In fact, obesity is the main risk factor for T2D, $85 \%$ and $80 \%$ of children and adults with T2D, respectively, have been individuals who were overweight or suffered from obesity before they presented T2D diagnosis.,

Mexico is a middle-income country ${ }^{7}$ in which diabetes is an important concern. In 2018, just after the United States, Mexico had the second highest rate of obesity in the world. The national survey of health and nutrition (2016) of Mexico reported obesity prevalence rates of $15.3 \%, 13.9 \%$, and $33.3 \%$ among children between the ages of 5 and 11 years old, 12 and 19 years old, as well as adults, respectively. ${ }^{8}$ The last report of the Organization for Economic Cooperation and Development Reviews of Health Systems in Mexico, reported $15.9 \%$ prevalence rate of T2D in the Mexican population in 2016. ${ }^{9}$ A study performed in Mexico City has shown that the previous diagnosed of diabetes has been associated with rate ratios of death by any cause, 5.4 for adults from 35 to 59 years old , 3.1 for adults from 60 to 74 years old, and 1.9 for adults from 75 to 84 years old. ${ }^{10}$ Additionally, this study reports that the largest absolute excess risks of death in previously diagnosed diabetes people were from renal disease, cardiac disease, infections, acute diabetic crises and other vascular diseases (mainly stroke). ${ }^{10}$

The Southern region in Mexico is integrated by the provinces of: Campeche, Chiapas, Guerrero, Oaxaca, Puebla, Tlaxcala, Quintana Roo, Tabasco, Veracruz, and Yucatán. In 2018, the Consejo Nacional de Evaluación de la Política de Desarrollo Social in México reported that the Southern, represents the region with the highest rate of population in poverty in the country. ${ }^{11}$ According to the national survey of health and nutrition (2016) in Mexico, the Southern region of the country has shown the highest prevalence of diabetes (10.2\%) in comparison with the North $(8.7 \%)$, the Center $(9.8 \%)$ and Mexico City $(8.3 \%){ }^{8}$ Regarding to the prevalence of adulthood obesity in Mexico, after the North region, it is the Southern region the one which had the second highest rate of obesity in Mexico. This data reveals that the population in the Southern region of Mexico are in high risk of developing diabetes and its complications.
Volume 4 Issue 5 - 2020

\author{
Consuelo Chang-Rueda, lliana Quezada- \\ Cruz, Claudia Galindo-Arcega, Marisol \\ Espinoza-Ruiz \\ Facultad de Ciencias Químicas, Campus IV Universidad \\ Autónoma de Chiapas, Tapachula, Chiapas, Mexico
}

\begin{abstract}
Correspondence: Consuelo Chang-Rueda, Facultad de Ciencias Químicas, Campus IV Universidad Autónoma de Chiapas. Carretera a Puerto Madero Km I.5, Colonia Centro, Tapachula, Chiapas, Mexico, Tel +52 962625I 555, Fax +52 962626246I,Email consuelo.chang@unach.mx
\end{abstract}

Received: July 30, 2020 | Published: September 28, 2020

Individuals with diabetes are in high risk of developing macrovascular (i.e. hypertension, myocardial infarction and stroke) and microvascular (i.e. diabetic nephropathy and complication related with the nervous system and retina) complications. According to longitudinal studies from developed countries, the risk of developing microvascular and macrovascular complications in individuals with diabetes is $10-20$ times higher and 2-4 times higher, respectively, than in individuals without diabetes. ${ }^{12}$ In comparison with developed countries, stroke and kidney are the most common complications in the developing countries and these complications have resulted in a high costly increase. For instance, in developed countries, $53 \%$ of the lifetime medical costs of $\mathrm{T} 2 \mathrm{D}$, have been attributed to treating the complications such as nephropathy, neuropathy, retinopathy, stroke and coronary heart diseases. ${ }^{13}$

The absence of observational and prospective studies of diabetes in the Southern region of Mexico makes it hard to precisely estimate their contributions to morbidity and mortality rates in the country. ${ }^{12}$ The development of observational and prospective studies of diabetes in the Southern region of Mexico could help us to understand the epidemiology of the diabetes and propose the patient management involving particular lifestyle modification and combination therapy of medication. ${ }^{14}$

\section{Conclusion}

Currently, the Southern region of México presents the highest prevalence of diabetes in the country $(10.2 \%)$, and this rate could increase in the coming years due to high frequency of adulthood obesity of such population. Exploring the epidemiology of diabetes 
through prospective studies, we could improve strategies to prevent the increase of the prevalence of diabetes and its complications among the population of Mexico.

\section{Acknowledgements}

None.

\section{Conflicts of interest}

No potential conflicts of interest relevant to this article were reported.

\section{References}

1. Cho NH, Shaw JE, Karuranga S, et al. IDF Diabetes Atlas: Global estimates of diabetes prevalence for 2017 and projections for 2045 . Diabetes Res Clin Pract. 2018;138:271-281.

2. Henning RJ. Type-2 diabetes mellitus and cardiovascular disease. Future Cardiol. 2018;14(6):491-509.

3. Fletcher B, Gulanick M, Lamendola C. Risk factors for type 2 diabetes mellitus. J Cardiovasc Nurs. 2002;16(2):17-23.

4. Pradeepa R, Mohan V. Prevalence of type 2 diabetes and its complications in India and economic costs to the nation. Eur J Clin Nutr. 2017;71(7):816-824.

5. Rosenbloom AL, Silverstein JH, Amemiya S, et al. ISPAD Clinical Practice Consensus Guidelines 2006-2007. Type 2 diabetes mellitus in the child and adolescent. Pediatr Diabetes. 2008;9(5):512-526.
6. Bloomgarden ZT. American Diabetes Association Annual Meeting, 1999: diabetes and obesity. Diabetes Care. 2000;23(1):118-124.

7. Bank TW. Mexico data. 2019

8. Shamah-Levy T, Ruiz-Matus C, Rivera-Dommarco J, et al. Encuesta Nacional de Salud y Nutrición de Medio Camino 2016. Resultados Nacionales. Cuernavaca, México: Instituto Nacional de Salud Pública (México). 2017.

9. OECD. OECD Reviews of Health Systems: Mexico 2016. Paris: OECD Publishing. 2016.

10. Alegre-Diaz J, Herrington W, Lopez-Cervantes M, et al. Diabetes and Cause-Specific Mortality in Mexico City. $N$ Engl $J$ Med. 2016;375(20):1961-1971.

11. CONEVAL. Información de pobreza y evaluación en las entidades federativas y municipios. Consejo Nacional de Evaluación de la Politica de Desarrollo Social, Mexico. 2018.

12. Gregg EW, Sattar N, Ali MK. The changing face of diabetes complications. Lancet Diabetes Endocrinol. 2016;4(6):537-547.

13. Zimmet PZ, Magliano DJ, Herman WH, et al. Diabetes: a $21^{\text {st }}$ century challenge. Lancet Diabetes Endocrinol. 2014;2(1):56-64.

14. Reusch JE, Manson JE. Management of Type 2 Diabetes in 2017: Getting to Goal. JAMA. 2017;317(10):1015-1016. 